\title{
AGGRESSIVE FIBROMATOSIS OF THE ABDOMINAL WALL: A CASE REPORT
}

Mohan S. V. S, B. V. Sushil Kumar

1. Assistant Professor, Department of Surgery, Shimoga Institute of Medical Sciences, Shimoga

2. Prof. \& Head, Department of Surgery, Shimoga Institute of Medical Sciences, Shimoga

\section{CORRESPONDING AUTHOR}

\section{Dr. Mohan S.V.S.}

"Sapthagiri". A.N.K. Road,

$1^{\text {st }}$ Cross, Achutharao Layout,

Shimoga, Karnataka.

E-mail: svs.mohan@yahoo.com

Ph: 00919844097444.

ABSTRACT: BACKGROUND: Desmoid tumors are slow growing deep fibromatosis with aggressive infiltration of the adjacent tissue but without any metastatic potential.

KEY WORDS: Desmoid; fibromatosis; abdominal; genotype; familial adenomatous polyposis; colonal neoplasm; surgery.

INTRODUCTION: Aggressive fibromatosis is a rare condition marked by the presence of desmoids tumors, which are benign, slow growing musculo- aponeurotic tumors without any metastatic potential. However aggressive fibromatosis is locally aggressive despite their benign nature. They can damage nearby structures causing organ dysfunction.

CASE REPORT: This is a case of 34 year old women with complains of mass in the right iliac fossa since 3 months, which was gradually increasing in size and she also had dragging pain in the mass. She also had constipation on and off. There was no history of fever, anorexia or trauma and repeated child birth.

Examination revealed are parietal wall swelling measuring about $13^{*} 12 \mathrm{~cm}$ which increased in size with restricted mobility on putting underlying muscle into contraction. Swelling was firm in consistency, tender on deep palpation with diffused border.

USG abdomen and FNAC of the mass in right iliac fossa revealed the possible diagnosis of desmoid tumor.

Laparotomy and wide excision of the tumor along with partial excision of internal oblique muscle with aponeurosis done and the gap in the musculo-aponeurotic region is closed by proline mesh after obtaining complete haemostasis. Wound closed with a corrugated drain in position which was removed after 72 hours.

DISCUSSION: Desmoids tumor, a rare type constitutes 3\% of all soft tissue tumors and $0.03 \%$ of all neoplasms. It usually develops in the arms, legs, abdomen and chest of children and adult. It is one of the components of Gardner's syndrome (familial polyposis coli with desmoids tumor and craniofacial osteoma, epidermoid cyst, congenital hypertrophy of retinal pigment epithelium)

Desmoid can occur anywhere in the body but generally occur in the root of mesentery (Intra-abdominal), in the abdominal wall (Abdominal desmoids) and outside the abdomen, primary in the shoulder or pelvic girdle (Extra-abdominal) 
It is an uncapsulated fibroma which occurs commonly in abdominal wall which involves muscle and aponeurotic layers of abdominal wall.

Although desmoids have a benign histological appearance they can invade locally often aggressively and recur repeatedly. Repeated child birth, trauma, operative scar are possible etiological factors.

Sarcomatous changes and metastasis does not occur.

Inspite of adequate surgery also, $10-20 \%$ chance of recurrence is known. Medical lines of treatment like SULINDAC and TAMOXIFEN have also been used with some success in cases of unresectable desmoid tumors.

The complete surgical wide excision is the recommended treatment for the desmoid tumor.

CONCLUSION: The desmoid tumor is a rare condition. Surgeons face challenges in both diagnosis and treatment of the tumor. The wide excision remains the gold standard surgical treatment with mesh repair. Recurrence is known if excision is not done properly.

\section{REFERENCES:}

1. Fletcher CDM: Myofibroblastic tumors: An update. Verh Dtsch Ges Path 1998,82: 75-82.

2. Lewis JJ, Boland PJ, Leung DH, Woodruff JM, Brennan MF. The enigma of desmoid tumors. Ann Surg. 1999; 229:866-867. [PubMed]

3. Dangel A, Meloni AM, Lynch HT, Sandberg AA. Deletion (5q) in a desmoid tumor of a patient with Gardner's syndrome. Cancer Genet Cytogenet. 1994; 78:94-98. [PubMed]

4. Hasegawa SL, Fletcher CDM. Fibromatosis in the adult. Adv Pathol. 1996; 9:259-275.

5. Soravia C, Berk T, Mcleod RS, Cohen Z. Desmoid disease on patients with familial adenomatous polyposis. Dis Colon Rectum. 2000; 43:363-369. [PubMed]

6. Gansar GF, Markowita IP, Cerise EJ. Thirty years of experience with desmoid tumors at charity hospital. Am Surg. 1987; 53:318-319. [PubMed]

7. Middleton SB, Philips RK. Surgery for large intra-abdominal desmoid tumors: report of four cases. Dis Colon Rectum 2000; 43:1759-1762. [PubMed]

8. Waddell WR, Kirsch WM: Testolactone, sulindac, warfarin and vitamin K1 for unresectable desmoid tumors. An J Surg 1991; 161:416-421. [PubMed]

9. Rock MG, Pritchard DJ, Reiman HM, Soule EH, Brewster RC: Extra-abdominal desmoid tumors. J Bone Joint Surg Am 1984; 66:1369-1374. [PubMed]

10. Sutton RJ, Thomas JM: Desmoid tumors of the anterior abdominal wall. Eur J Surg Oncol 1999; 25:398-400. [PubMed]

11. Mentzel T, KatenkampD: Myofibroblastic tumors. Brief review of clinical aspects, diagnosis and differential diagnosis. Pathologe 1998; 19:176-186. [PubMed]

12. Shields CJ, Winter DC, Kirwan WO, Redmond HP: Desmoid tumors. Eur J Surg Oncol 2001; 27:701-706. [PubMed] 


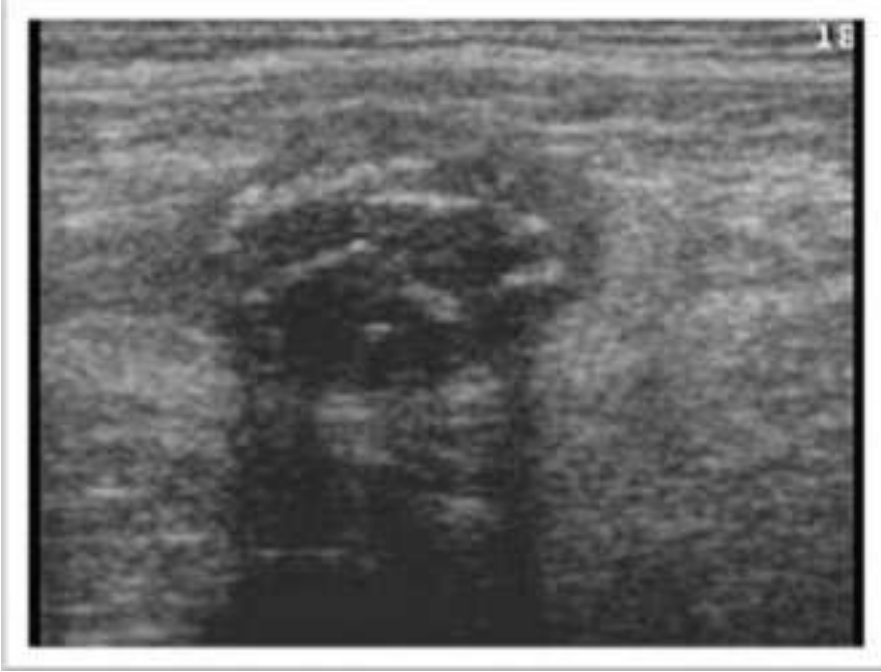

Figure 1: USG- Right lower anterior abdominalis muscle, well defined hypoechoic massDesmoid tumor

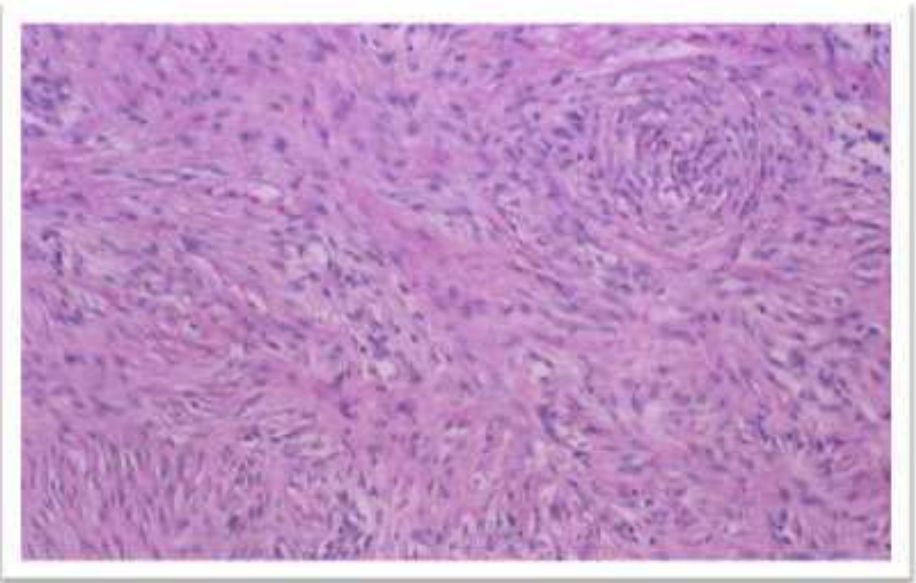

Figure 2: FNAC- smears are moderately cellular and spindle shaped cells arranged in small fascicles and seen dispersing. Regular spindle shaped bland nuclei with moderate cytoplasm. No mitosis/atypical cells seen. Benign soft tissue possibly Desmoid tumor. 


\section{CASE REPORT}

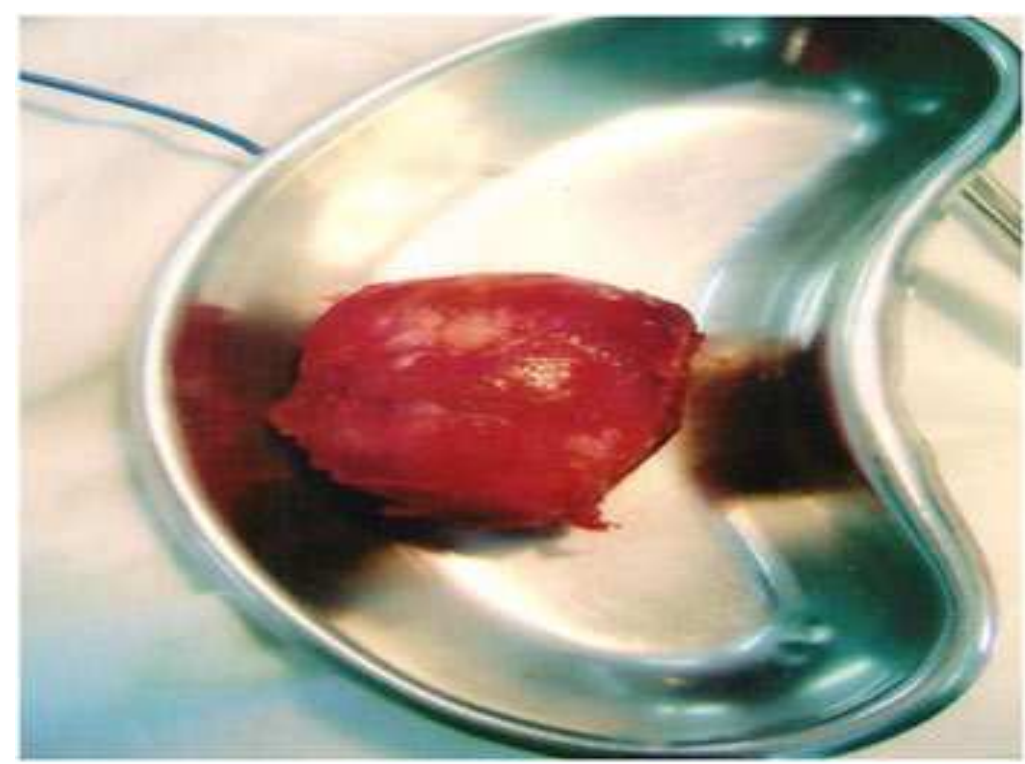

Figure 3: Operative specimen of the tumor

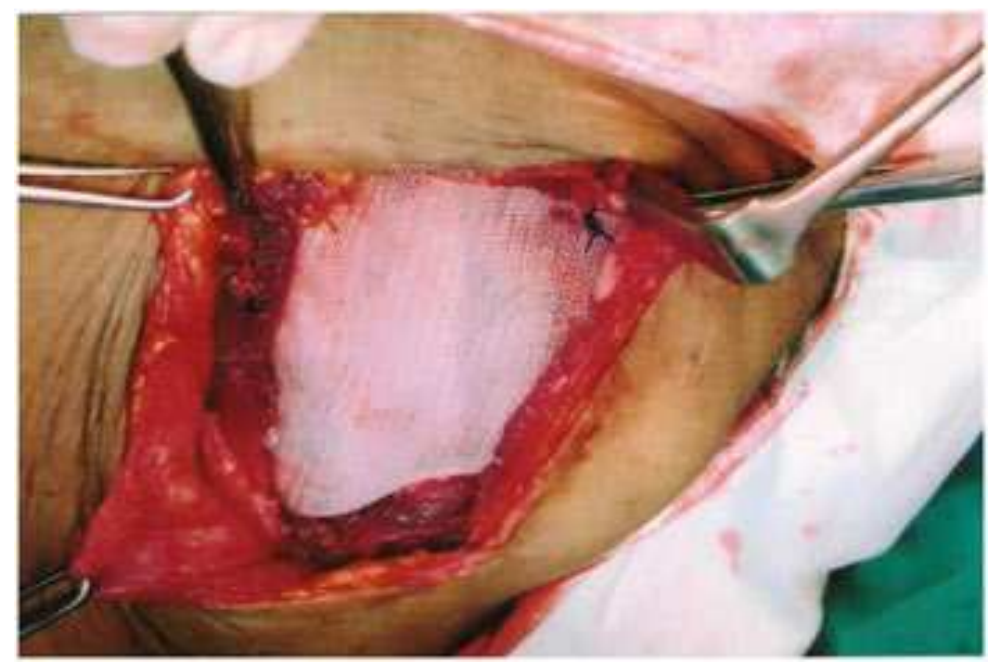

Figure 4: After resection of the desmoid tumor the abdominal wall defect is replaced with the proline mesh. 


\section{CASE REPORT}

The final histopathological report showed musculoaponeurotic fibromatosis.

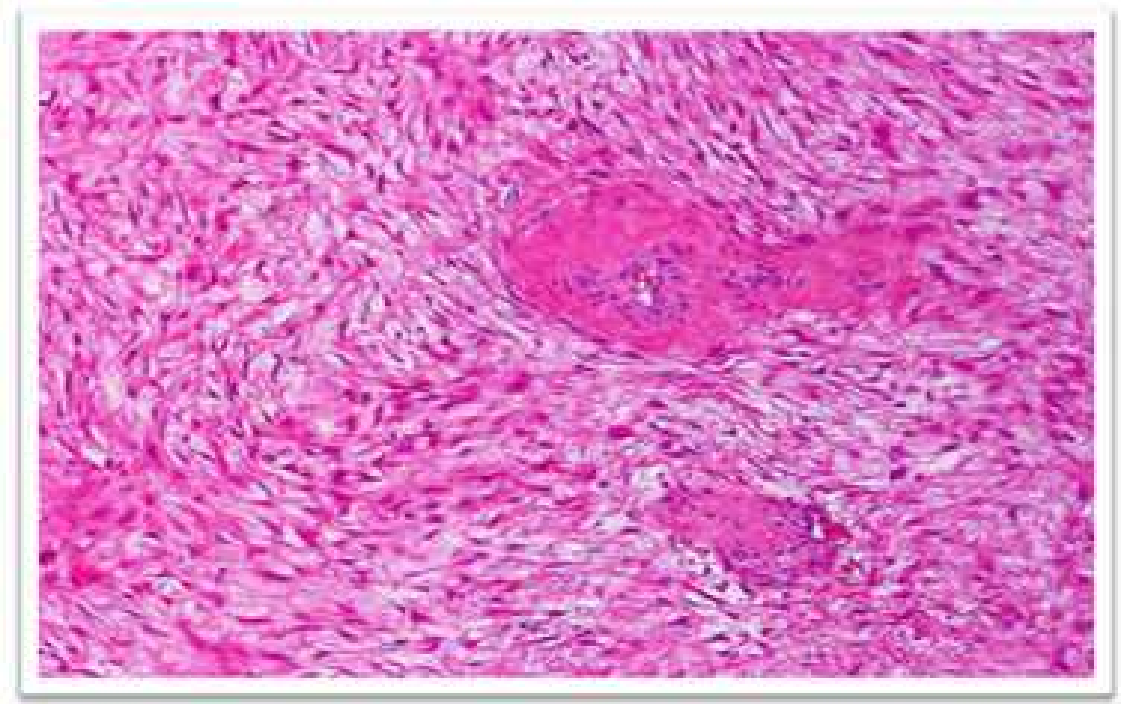

Figure 5: Interlacing, ill defined fascicles of fibroblast which has spindle shaped nuclei and cytoplasm 